\title{
Risk factors of microvascular invasion in patients with hepatocellular carcinoma.
}

\author{
Yan Zhang*, Wanjing Yang, Jingli Ren \\ Department of Pathology, the Second Affiliated Hospital of Zhengzhou University, Hennan Province, 450014, PR \\ China
}

\begin{abstract}
Background: It is suggested that microvascular invasion (MVI) is one of the strongest predictors of prognosis and recurrence of hepatocellular carcinoma (HCC). This study analyzes the related influence factors of MVI, and further discusses these factors to the occurrence of MVI.

Method: Retrospective clinical data of HCC patients which are collected, including the general clinical data and postoperative pathological data associated with MVI are performed. According to the postoperative pathological report, data will be divided into MVI group and control group. Logistic regression analysis was performed on the statistically significant factors.

Results: A total of 170 patients with $\mathrm{HCC}$ are selected. There are MVI group (51 cases) and control group ( 97 cases). There were no significantly differences in age, gender, history of hepatitis B, history of hepatitis $\mathbf{C}$, hepatic cirrhosis, diabetes and hepatitis B virus deoxyribonucleic acid titer, $\gamma$ - glutamyltranspeptidas, alanine transaminase, aspartate transaminase, total bilirubin, albumin, platelet count, tumor numberand tumor capsule $(P>0.05)$. Tumor size $(P=0.000)$, differentiation degree $(P=0.028)$ and alpha-fetoprotein $(P=0.003)$ was statistically significant difference. Multivariate logistic regression analysis shows that tumor size $(P=\mathbf{0 . 0 0 4})$ and $\mathrm{AFP}(P=\mathbf{0 . 0 2 2})$ are independent risk factors for MVI.

Conclusion: Tumor size, low differentiation, tact capsule and alpha-fetoprotein are independent risk factors of MVI. According to the risk factors of MVI, we can judge the possibility of MVI, and further guide the clinical treatment.
\end{abstract}

Keywords: Microvascular invasion, Hepatocellular carcinoma, Risk factors.

Accepted on November 15, 2017

\section{Introduction}

Primary liver cancer (PLC) is one of the most common malignant tumors, and among $\mathrm{HCC}$, more than $90 \%$ is hepatocellular carcinoma (HCC) [1]. Of all the malignant tumors, the clinical morbidity of HCC ranks second in male patients and sixth in female patients. Each year 782500 patients are diagnosed with $\mathrm{HCC}$, with a mortality rate of $95 \%$ [2]. Half of the world's share of HCC occurs in China, thus making HCC a severe health problem of the country [3]. In the past several decades, great changes have taken place in clinical diagnostic and treatment of HCC with the development of technology such as intervention, radiofrequency ablation, radiotherapy and chemotherapy, and biological therapy [4-6]. The widely application of early screening makes HCC being early detection as well as early diagnostic and treatment, even for end-stage patients. These methods are still limited, and operative treatment is still primary method for HCC [7]. More seriously, some postoperative complications are still concerned [8].

Previous studies found that tumor size, number, vascular invasion were independently prognostic factors of HCC [9].
Microvascular invasion is a way of blood metastasis of hepatocellular carcinoma, and has been repeatedly confirmed to be associated with tumor recurrence rate and overall survival rate. Vascular invasion is divided into macrovascular invasion (MVI) and microvascular invasion [10]. The macrovascular invasion was involved in secondary and above hepatic vein or portal vein [11]. MVI in primary liver cancer pathology guide was defined as HCC cell mass were found in portal vein and hepatic vein or other microvasculars surrounded by endothelial cells. The recurrence rate of tumor with vascular invasion was 4.4 and 15 times than that of non-vascular invasion [12]. So, early identification of MVI was quite important. Early identification means early diagnostic and treatment, and reduces tumor recurrence and metastasis, improves patient's survival rate and quality of life. Therefore, it is of great significance to judge whether there is MVI or not before surgery [13]. The purpose of this study was to explore the correlation between preoperative and pathological data of HCC patients and MVI, and provided clinical guidance for MVI treatment. 


\section{Materials and Methods}

\section{Study population}

Using a retrospective design, $170 \mathrm{HCC}$ patients were enrolled in our hospital from December 2014 to December 2016. The general clinical data, serum index, and postoperative pathological data were collected according to the following criteria: patients were diagnosed with $\mathrm{HCC}$ according to Chinese HCC guideline, and confirmed by pathology detection, whose age were more than 18 years old, no other new tumors within 5 years, no bone and other metastatic, and have complete clinical and pathology information for extraction and analyses.

\section{Diagnostic criteria}

The HCC was diagnosed as the following criteria [14]: (1) history of hepatitis $\mathrm{B} / \mathrm{C}$ virus infection. (2) Typical HCC imaging features: multi-row $\mathrm{CT}$ and/or enhanced MRI scans showed rapid and unequal arterial enhancement in arterial phase, while venous or delayed periods were quickly eluded. (3) Alpha fetoprotein (AFP) $\geq 400 \mathrm{ug} / \mathrm{L}$ lasted for one month and excluded other reasons. (4) The postoperative pathological report was referred. The MVI criteria was as follows: according to the 2015 HCC standardized pathological diagnosis guide, imaging examination or not seen obvious intravascular tumor emboli. Tumor emboli or lumps of cancer cells in capillaries were found with the help of microscopic [15].

\section{Data collection}

The general clinical data (age, gender, history of hepatitis B, history of hepatitis C, history of cirrhosis and history of diabetes), serum index (alpha-fetoprotein (enzyme linked immunosorbent assay), hepatitis B virus DNA titer, $\gamma$ glutamyltransferase, alanine transaminase, aspartate transaminase, total bilirubin, albumin and platelet count) and postoperative pathological data (tumor size, tumor number, tumor differentiation and tumor capsule) were collected. The serum index was from the automatic biochemical analyzer (Hitachi 7600-020ISE, Japan).

\section{Statistical analysis}

All statistical analysis was performed by using SPSS 20.0. For the continuity variables were expressed by using the mean addition and subtraction standard deviation, and test were used. The classification data were expressed as percentage and count and chi-square test was used. Using the correlation analysis method of univariate, the correlation of clinical data, serum indexes, postoperative pathological parameters and MVI are valued. Logistic regression analysis was performed on the statistically significant factors (AFP, tumor size, differentiation degree, intact capsule.), MVI status are identified as independent risk factors. $\mathrm{P}<0.05$ is considered statistically significant difference.

\section{Results}

A total of 170 patients with HCC are selected, including male $(n=119)$, and female $(n=51)$, mean age $(57.1 \pm 9.38)$ years. There are MVI group (65 cases) and control group (105 cases). Of these, $81.5 \%$ of them have HBV infection in MVI group, and $82.9 \%$ in the control group, and there was no significant between two groups $\left(\chi^{2}=0.048, \mathrm{P}=0.826\right) .7 .7 \%$ of them have $\mathrm{HCV}$ infection in the MVI group while the rate was 3.8\%, and no significant difference was observed $\left(\chi^{2}=1.207, \mathrm{P}=0.271\right)$. The rates of liver cirrhosis were $73.8 \%$ and $80.9 \%$ in two groups, respectively, and no obvious significant difference was observed $\left(\chi^{2}=1.191, \mathrm{P}=0.275\right)$. There was no significantly difference in diabetes mellitus rate between two groups $\left(\chi^{2}=0.814, \mathrm{P}=0.367\right)$. The general characteristics of two groups were presented in Table 1.

Table 1. Comparisons of general characteristics between two groups.

\begin{tabular}{lllll}
\hline Parameters & $\begin{array}{l}\text { MVI group } \\
(\mathbf{6 5 )}\end{array}$ & $\begin{array}{l}\text { Control } \\
\text { group } \\
\mathbf{( 1 0 5 )}\end{array}$ & $\mathbf{t} / \mathbf{X}^{2}$ & $\mathbf{P}$ \\
\hline Age, year & $56.4 \pm 10.4$ & $57.6 \pm 11.2$ & -0.697 & 0.487 \\
\hline Male, $\mathrm{n}$ & $45(69.2 \%)$ & $74(70.5 \%)$ & 0.030 & 0.863 \\
\hline History of diseases & & & & \\
\hline HBV, $\mathrm{n}$ & $53(81.5 \%)$ & $87(82.9 \%)$ & 0.048 & 0.826 \\
\hline HCV, $\mathrm{n}$ & $5(7.7 \%)$ & $4(3.8 \%)$ & 1.207 & 0.271 \\
\hline Liver cirrhosis, $\mathrm{n}$ & $48(73.8 \%)$ & $85(80.9 \%)$ & 1.191 & 0.275 \\
\hline Diabetes mellitus, $\mathrm{n}$ & $10(15.4 \%)$ & $22(21.0 \%)$ & 0.814 & 0.367 \\
\hline
\end{tabular}

*MVI, macrovascular invasion; HBV, hepatitis B virus; $\mathrm{HCV}$, hepatitis $\mathrm{C}$ virus

The serum analysis results showed that there were no differences in hepatitis $\mathrm{B}$ virus DNA $(\mathrm{P}=0.582), \gamma$-GT ( $\mathrm{P}=0.069)$, ALT $(\mathrm{P}=0.469)$, AST $(\mathrm{P}=0.075)$, total bilirubin $(\mathrm{P}=0.737)$, albumin $(\mathrm{P}=0.226)$, platelet count $(\mathrm{P}=0.295)$. The different ratio of each index was presented in Table 2 . The results of pathology characteristics suggested that the MVI group had larger tumor size than that of control group (5.7 \pm 4.3 vs. $3.7 \pm 4.2, \mathrm{P}=0.003)$, and the MVI group had lower level differentiation compared with control group (49.2\% vs. $28.6 \%$, $\mathrm{P}=0.025)$. The MVI group was still higher than control group in intact capsule rate $(44.6 \%$ vs. $33.3 \%, \mathrm{P}=0.015)$. There was not statistically significant in tumor number between two group $(\mathrm{P}=0.140)$. Multivariate logistic regression analysis shows that tumor size $\quad(\mathrm{P}=0.004)$, alpha-fetoprotein $\quad(\mathrm{P}=0.015)$, differentiation $(\mathrm{P}=0.003)$, and intact capsule $(\mathrm{P}=0.009)$ were independent risk factors for MVI in patients with HCC. The larger tumor size means higher risk $(\mathrm{OR}=1.19,95 \% \mathrm{CI}$ : 1.05-1.33). Compared with high differentiation, the medium and low differentiation patients were higher risk by $39 \%$ and $89 \% \quad(\mathrm{OR}=1.39, \quad 95 \% \mathrm{CI}: \quad 1.12-3.26 ; \quad \mathrm{OR}=1.89, \quad 95 \% \mathrm{CI}$ : 1.02-3.66). The high level AFP also means higher risk of MVI 
$(\geq 400: 1.37,95 \% \mathrm{CI}: 1.17-1.61 ; 20-400: \mathrm{OR}=1.05,95 \% \mathrm{CI}$ $1.01=2.13$ ) (Tables 3 and 4).

Table 2. Comparisons of serum marker between two groups.

\begin{tabular}{|c|c|c|c|c|}
\hline Parameters & $\begin{array}{l}\text { MVI group } \\
(65)\end{array}$ & $\begin{array}{l}\text { Control group } \\
(105)\end{array}$ & $x^{2}$ & $\mathbf{P}$ \\
\hline AFP, ug/L & & & 12.989 & 0.002 \\
\hline$\leq 20$ & $26(40.0 \%)$ & $68(64.8 \%)$ & & \\
\hline $20-400$ & $20(30.8 \%)$ & $26(24.8 \%)$ & & \\
\hline$\geq 400$ & $19(29.2 \%)$ & $11(10.5 \%)$ & & \\
\hline HBV-DNA, IU/ml & & & 1.081 & 0.582 \\
\hline$\leq 500$ & $35(53.8 \%)$ & $65(61.9 \%)$ & & \\
\hline $500-10000$ & $14(21.5 \%)$ & $19(18.1 \%)$ & & \\
\hline$\geq 10000$ & $16(24.6 \%)$ & $21(20.0 \%)$ & & \\
\hline $\mathrm{V}-\mathrm{GT}, \mathrm{U} / \mathrm{L}$ & & & 3.293 & 0.069 \\
\hline$\geq 60$ & $26(40.0 \%)$ & $28(26.7 \%)$ & & \\
\hline$<60$ & $39(60.0 \%)$ & $77(73.3 \%)$ & & \\
\hline Platelet, 109 & & & 1.097 & 0.295 \\
\hline$\geq 100$ & $51(78.5 \%)$ & $89(84.8 \%)$ & & \\
\hline$<100$ & $14(21.5 \%)$ & $16(16.2 \%)$ & & \\
\hline Albumin, g/L & & & 1.463 & 0.226 \\
\hline$\geq 35$ & $27(41.5 \%)$ & $34(32.4 \%)$ & & \\
\hline$<35$ & $38(58.5 \%)$ & $71(67.6 \%)$ & & \\
\hline Total bilirubin, umol/L & & & 0.113 & 0.737 \\
\hline$\geq 17.1$ & $28(43.1 \%)$ & $48(45.7 \%)$ & & \\
\hline$<17.1$ & $37(56.9 \%)$ & $57(54.3 \%)$ & & \\
\hline ALT, U/L & & & 0.524 & 0.469 \\
\hline$>44$ & $23(35.4 \%)$ & $43(41.0 \%)$ & & \\
\hline$\leq 44$ & $42(64.6 \%)$ & $62(59.0 \%)$ & & \\
\hline AST, U/L & & & 3.167 & 0.075 \\
\hline$>64$ & $14(21.5 \%)$ & $12(11.4 \%)$ & & \\
\hline$\leq 64$ & $51(78.5 \%)$ & $93(88.6 \%)$ & & \\
\hline
\end{tabular}

\section{Discussion}

Previous study suggested that MVI was primary way for HCC metastasis. Therefore, it was of great importance to explore the prognosis factors of MVI in patients with HCC. The present study found that tumor size, low differentiation, tact capsule and AFP are independent risk factors of MVI. Our results provided further guide for clinical treatment.

Table 3. Comparisons of tumor pathology between two groups.

\begin{tabular}{lllll}
\hline Parameters & MVI group & $\begin{array}{l}\text { Control } \\
\text { group }\end{array}$ & $t / X^{2}$ & $P$ \\
\hline
\end{tabular}

\begin{tabular}{lllll} 
& $\mathbf{( 6 5 )}$ & $\mathbf{( 1 0 5 )}$ & & \\
\hline Tumor size, cm & $5.7 \pm 4.3$ & $3.7 \pm 4.2$ & 2.989 & 0.003 \\
\hline Tumor number, $\mathrm{n}$ & & & \\
\hline single & $36(55.4 \%)$ & $70(66.7 \%)$ & 2.177 & 0.140 \\
\hline multiple & $29(44.6 \%)$ & $35(33.3 \%)$ & & \\
\hline Differentiation & & & \\
\hline High, n & $8(12.3 \%)$ & $18(17.1 \%)$ & & \\
\hline Medium, n & $25(38.5 \%)$ & $57(54.3 \%)$ & & \\
\hline Low, n & $32(49.2 \%)$ & $30(28.6 \%)$ & & 0.015 \\
\hline Intact capsule, yes & $29(44.6 \%)$ & $35(33.3 \%)$ & 5.863 & \\
\hline
\end{tabular}

*AFP: Alpha-Fetoprotein; HBV: Hepatitis B Virus; HCV: Hepatitis C Virus; $y-G T$ : Glutamyl-Transpeptidase

Table 4. Multiple logistic regression for MVI in patients with hepatocellular carcinoma.

\begin{tabular}{llllll}
\hline Factors & $\boldsymbol{\beta}$ & SE & OR & $95 \% \mathrm{CI}$ & $\mathbf{P}$ \\
\hline Tumor size & 0.171 & 0.060 & 1.19 & $1.05-1.33$ & 0.004 \\
\hline Differentiation & & & & & \\
\hline High & & & 1.00 & & \\
\hline Medium & 0.332 & 0.195 & 1.39 & $1.12-3.26$ & 0.015 \\
\hline Low & 0.640 & 0.336 & 1.89 & $1.02-3.66$ & 0.007 \\
\hline AFP & & & & & \\
\hline$\leq 20$ & & & 1.00 & & 0.003 \\
\hline $20-400$ & 0.047 & 0.036 & 1.05 & $1.01-2.13$ & 0.000 \\
\hline$\geq 400$ & 0.314 & 0.081 & 1.37 & $1.17-1.61$ & 0.000 \\
\hline Intact capsule (NO) & 0.248 & 0.096 & 1.28 & $1.06-1.55$ & 0.009 \\
\hline *AFP: Alpha-Fetoprotein & & & & & \\
\hline
\end{tabular}

Tumor size was related to MVI in patients with HCC. It was reported that tumor size with the size of more than $7 \mathrm{~cm}$, and the risk of MVI increased by 1 time. If the tumor size was more than $10 \mathrm{~cm}$, it would be more likely to have MVI. Tumor size (3-5 cm) can predict MVI better [16]. However, Chandarana reported that tumor size had no predictive effect on MVI, and the average diameter of the tumor selected by the author was $2.1 \mathrm{~cm}$, which may be considered to be the cause of the small average tumor in the selected patients [17]. Most studies suggested tumor size can predict microvascular invasion, MVI group in this study mean tumor size was $5.7 \pm$ $4.3 \mathrm{~cm}$, without vascular invasion significantly greater than 3.7 $\pm 4.2 \mathrm{~cm}$, which paralleled with previous results [18]. Differentiation level was associated with MVI. Low differentiation tumor tends to be malignant. It was more likely to have metastasis for such types of tumor. Previous studies have suggested that MVI was primary way of HCC metastasis. Our results found that low and medium differentiation types were higher than that of high differentiation ones by 1.89 and 1.39 times compared. 
The capsule of primary liver cancer showed low signal arterial ring or low density image through conventional enhanced CT/MRI performance for, and high density or high signal ring during delay period. Some studies reported that $10 \%-70 \%$ of primary hepatocellular carcinoma was covered by capsule, which was related to the histopathological classification, and the intact capsule was related to the occurrence of MVI [19]. This indicates that the intact HCC had a lower incidence of MVI. However, Gouw found no significant correlation was found between tumor capsule and MVI in imaging examination [20]. Witjes confirmed that MVI had a close relationship with the intact capsule [21]. Adachi reported that fibrous capsule may be a risk factor for portal vein invasion, suggesting that liver tumor cells are more likely to invade capsule vessels [22]. The above two studies did not further assess the difference of imaging stages. According to the features of HCC blood supply, the capsule can be enhanced in all stages, and it is difficult to distinguish the relationship between the surrounding tissue and the capsule through the early enhancement of imaging. Therefore, some scholars further studied the imaging performance of HCC in delayed period, and suggested that the tumor capsule and tumor boundaries were not fully used to predict MVI. To sum up, there is still a lot of debate about the correlation between the presence of the tumor capsule and occurrence of MVI, and further research is needed. Some study limitation should be addressed. First, this is a retrospective study, and it was restricted in cause-effect relationship. The long-term follow-up was required. Second, this was based on the investigation of clinical information, and was not involved in physiological mechanism. Further research is needed.

Tumor size, low differentiation, tact capsule and AFP are independent risk factors of MVI. According to the risk factors of MVI, we can judge the possibility of MVI, and further guide the clinical treatment. This study provides some theoretical support for the preoperative prediction of MVI. Because of the limited number of patients in the study, further studies are needed.

\section{References}

1. El-Serag HB. Advances in the management of hepatocellular carcinoma. Clin Adv Hematol Oncol 2017; 15: 2-6.

2. Chen W, Zheng R, Baade PD, Zhang S, Zeng H, Bray F, Jemal A, Yu XQ, He J. Cancer statistics in China, 2015. CA Cancer J Clin 2016; 66: 115-132.

3. Niu J, Lin Y, Guo Z, Niu M, Su C. The epidemiological investigation on the risk factors of hepatocellular carcinoma: a case-control study in southeast China. Medicine (Baltimore) 2016; 95: e2758.

4. Rinninella E, Cerrito L, Spinelli I, Cintoni M, Mele MC, Pompili M, Gasbarrini A. Chemotherapy for hepatocellular carcinoma: Current evidence and future perspectives. J Clin Transl Hepatol 2017; 5: 235-248.

5. Xie J, Chen Y, Meng F, Shu T, Liu Y, Zhang L, Zhang ZX. Study on the relationship between the RASSF10 gene and the biological behavior of hepatocellular carcinoma cells. Eur Rev Med Pharmacol Sci 2017; 21: 3576-3580.

6. Colquhoun SD. Hepatocellular carcinoma: The current role of surgical intervention. Crit Rev Oncog 2016; 21: 93-103.

7. Zamora-Valdes D, Taner T, Nagorney DM. Surgical treatment of hepatocellular carcinoma. Cancer Control 2017; 24: 1145164522.

8. Huang YS, Chang CC, Chang YC. A rare complication after transarterial chemoembolization for hepatocellular carcinoma. QJM 2014; 107: 487-488.

9. Higaki T, Yamazaki S, Moriguchi M, Nakayama H, Kurokawa T, Takayama T. Indication for surgical resection in patients with hepatocellular carcinoma with major vascular invasion. Biosci Trends 2017.

10. Pesi B, Ferrero A, Grazi GL, Cescon M, Russolillo N, Leo F, Boni L, Pinna AD, Capussotti L, Batignani G. Liver resection with thrombectomy as a treatment of hepatocellular carcinoma with major vascular invasion: results from a retrospective multicentric study. Am J Surg 2015; 210: 35-44.

11. Zhao H, Hua Y, Lu Z, Gu S, Zhu L, Ji Y, Qiu Y, Dai T, Jin H. Prognostic value and preoperative predictors of microvascular invasion in solitary hepatocellular carcinoma $\leq 5 \mathrm{~cm}$ without macrovascular invasion. Oncotarget 2017; 8: 61203-61214.

12. Li SH, Guo ZX, Xiao CZ, Wei W, Shi M, Chen ZY, Cai MY, Zheng L, Guo RP. Risk factors for early and late intrahepatic recurrence in patients with single hepatocellular carcinoma without macrovascular invasion after curative resection. Asian Pac J Cancer Prev 2013; 14: 4759-4763.

13. Pusceddu C, Melis L, Ballicu N, Sotgia B, Melis M, Sanna V, Meloni GB, Porcu A, Fancellu A. Percutaneous microwave ablation under CT guidance for hepatocellular carcinoma: A single institutional experience. J Gastrointest Cancer 2017.

14. Sastre J, Diaz-Beveridge R, Garcia-Foncillas J, Guardeno R, Lopez C, Pazo R, Rodriguez-Salas N, Salgado M, Salud A, Feliu J. Clinical guideline SEOM: hepatocellular carcinoma. Clin Transl Oncol 2015; 17: 988-995.

15. Du M, Chen L, Zhao J, Tian F, Zeng H, Tan Y, Sun H, Zhou J, Ji Y. Microvascular invasion (MVI) is a poorer prognostic predictor for small hepatocellular carcinoma. Bmc Cancer 2014; 14: 38.

16. Nagano Y, Shimada H, Takeda K, Ueda M, Matsuo K, Tanaka K, Endo I, Kunisaki C, Togo S. Predictive factors of microvascular invasion in patients with hepatocellular carcinoma larger than $5 \mathrm{~cm}$. World J Surg 2008; 32: 2218-2222.

17. Chandarana H, Robinson E, Hajdu CH, Drozhinin L, Babb JS, Taouli B. Microvascular invasion in hepatocellular carcinoma: is it predictable with pretransplant MRI? AJR Am J Roentgenol 2011; 196: 1083-1089.

18. Kubo S, Nishiguchi S, Hirohashi K, Shuto T, Kuroki T, Minamitani S, Ikebe T, Yamamoto T, Wakasa K, Kinoshita H. Clinicopathological criteria for multicentricity of 
hepatocellular carcinoma and risk factors for such carcinogenesis. Jpn J Cancer Res 1998; 89: 419-426.

19. Lim JH, Choi D, Park CK, Lee WJ, Lim HK. Encapsulated hepatocellular carcinoma: CT-pathologic correlations. Eur Radiol 2006; 16: 2326-2333.

20. Gouw AS, Balabaud C, Kusano H, Todo S, Ichida T, Kojiro M. Markers for microvascular invasion in hepatocellular carcinoma: where do we stand? Liver Transpl 2011; 17: S72-S80.

21. Witjes CD, Willemssen FE, Verheij J, van der Veer SJ, Hansen BE, Verhoef C, de Man RA, Ijzermans JN. Histological differentiation grade and microvascular invasion of hepatocellular carcinoma predicted by dynamic contrast-enhanced MRI. J Magn Reson Imaging 2012; 36: 641-647.
22. Adachi E, Maeda T, Kajiyama K, Kinukawa N, Matsumata T, Sugimachi K, Tsuneyoshi M. Factors correlated with portal venous invasion by hepatocellular carcinoma: univariate and multivariate analyses of 232 resected cases without preoperative treatments. Cancer-Am Cancer Soc 1996; 77: 2022-2031.

\section{*Correspondence to}

Yan Zhang

Department of Pathology

The Second Affiliated Hospital of Zhengzhou University

PR China 